\title{
Discontinuous Change in University Web Sites: The Relative Importance of Reasons for Change
}

\author{
Terry Ryan \\ Claremont Graduate University, \\ Claremont, CA, USA
}

terry.ryan@cgu.edu

\author{
Richard H.G. Field \\ University of Alberta, \\ Edmonton, AL, Canada \\ richard.field@ualberta.ca
}

\author{
Lorne Olfman \\ Claremont Graduate University, Claremont, CA, USA \\ lorne.olfman@cgu.edu
}

\begin{abstract}
An examination of prior Web pages shows that the typical university will sometimes make a discontinuous change to its Web site (i.e., a sudden, major shift in a Web site between two points in time). This exploratory empirical study examines reasons for such discontinuous changes, surveying university Webmasters at a variety of institutions where discontinuous Web site changes had occurred. Universities varied by type (public, private), by level (Bachelors, Masters, $\mathrm{PhD}$ ), and by nation (Canada, USA). Four reasons for discontinuous Web site change, identified in an earlier study of discontinuous Web site change in state governments, were compared: rational, marketing, political, and institutional. According to the university Webmasters surveyed, rational reasons for change were most important, followed by marketing, institutional, and political reasons, in that order. The ordering of reasons reflects statistically significant differences among types of reasons. Results did not vary by type, level, or nation.
\end{abstract}

Keywords: discontinuous change, university, web site

\section{Introduction}

In the fall of 2001, the Internet Archive (web.archive.org) made available "the Wayback Machine," a free tool for gaining access to archived versions of over 10 billion Web pages. This site provides a capability for viewing many, if not most, Web sites published to the Web from 1996 to the present. Our exploration of this archival site led us to look at many Web sites and how they had changed over time.

Material published as part of this journal, either on-line or in print, is copyrighted by the Informing Science Institute. Permission to make digital or paper copy of part or all of these works for personal or classroom use is granted without fee provided that the copies are not made or distributed for profit or commercial advantage AND that copies 1) bear this notice in full and 2) give the full citation on the first page. It is permissible to abstract these works so long as credit is given. To copy in all other cases or to republish or to post on a server or to redistribute to lists requires specific permission and payment of a fee. Contact Publisher@InformingScience.org to request redistribution permission.
In a prior study of official US state government Web sites-i.e., those having the Web address www.state.xx.us, where $\mathrm{xx}$ is one of the 50 two-letter state codes - we noticed that 48 of 50 had undergone at least one discontinuous change in the period 1996-2001 (Ryan, Field, \& Olfman., 2003). We defined a discontinuous change as a sudden, major shift in a Web site between two points in 
time. We make a distinction between discontinuous changes and incremental ones, such as those that occur with normal maintenance of Web sites. Discontinuous changes to sites involve more than mere alterations in appearance, such as changes in the number, nature, and organization of pages that constitute a site.

While doing this study, we wondered what the reasons for discontinuous Web site changes could be. What might cause an organization to change its Web site in a discontinuous way, rather than an incremental one? We developed a questionnaire to measure the extent to which Web site change was caused by each of four distinct reasons for change, discussed below. After we became confident we had a reliable instrument for measuring the reasons for Web site change, we decided to study a larger population. We chose universities for a number of reasons.

The most obvious of these, if not the most important, is that we are all university employees and have an interest in how they, as a population of organizations, work. Universities are important organizational forms, having existed for many years and being likely to continue to exist for many years to come. Understanding why universities make discontinuous changes to their Web sites seemed to us to be a worthwhile goal.

The second reason we chose universities as the focus of our study is that almost all of them in the United States and Canada have Web sites, even if unsophisticated ones. There is a great deal of variation in what universities do with their Web sites, how long they have been doing it, and (presumably) why. This seemed to be fertile ground for research. Another reason we chose universities is that a large number of them exist in the United States and Canada.

A final reason we chose to study universities is that they can be categorized easily by the highest degrees they grant and by their statuses as public or private institutions, among other characteristics. We felt that universities of different types might differ in terms of the reasons they had made discontinuous changes to their Web sites. We decided to study the importance of the four types of explanation for discontinuous changes in Web sites, discussed above, across different types of universities.

\section{Literature Review}

We looked at the academic literature to identify classes of explanation for why changes to Web sites might occur. There is almost no existing research literature directly related discontinuous change in Web sites.

Aoyama (2002) studied the rapid evolution of mobile phone software systems, examining continuous and discontinuous change in phone software. The study concluded that discontinuity is an essential aspect of software evolution, having to do with adaptation of software to essential change in the environments and requirements for computing. The study observed several discontinuous changes in the evolution of mobile phone software: from simple voice communication to digital communication to mobile Internet to Java-enabled systems. Aoyama claims that discontinuity follows from rapid and substantial change in architecture and features - at each discontinuous change, a large extension of architecture and a large set of new requirements were observed, both leading to substantial changes in code. Demands for changes in architecture and features are not unusual, being driven by a variety of pressures, but can exceed critical levels of "tolerance to change," after which a discontinuous change occurs. This tolerance to change is a property of the organization, indicating "the level of change that the system can elaborate to adopt changes or requirements and environments" (p. 88). Aoyama asserts that discontinuous change is important because it constitutes a major stress to software development, and understanding how it could be tamed should be a topic for software development research. 
Fetterly, Manasse, Najork, and Wiener (2004) studied the extent of change in Web pages, examining 150,836,209 $\mathrm{html}$ pages once every week for 11 weeks, through the use of Web crawling software. Their indicator of page change was a checksum that they compared from week to week for each site. They also saved and examined the full text of $0.1 \%$ of all pages that they tracked, considering for these what had been the nature of the change. They found that the amount of change is related to the size of the page, although the relationship varies widely. They did not consider the reasons that changes, of any magnitude, occurred.

Azzone, Bianchi, and Noci (2000) conducted an analysis of the Web sites of 39 companies at two points in time, six months apart. They examined each site in terms of tools that it could implement. On the basis of this, they determined that Web sites can attain two basic configurations: a communication phase, characterized by information flows, and a transaction phase, characterized by exchange of products. They observed that Web sites move from one configuration to another. As they move from one configuration to another, new tools tend to be added, but existing tools tend to remain. Tools increase in quality, with more detail, better description, and better organization. Information content evolves from mono-directional-simple to mono-directional-mature/bidirectional-simple to bi-directional-mature. Movement of Web sites along an evolutionary path is explained in terms of internal and external learning processes and increasing complexity. The implication of the study is that, for the most part, Web sites display incremental, predictable change.

Aside from Web sites and technology in particular, the literature about organizational change is immense and diverse, with change here also being conceptualized as either discontinuous (episodic) or continuous (Weick \& Quinn, 1999). Change research draws on many different perspectives and backgrounds, including rational models of decision making (Dawson, 2000; Gooderham, Nordhaug, \& Ringdal, 1999), communicative analyses (Barrett \& Heracleous, 2001), political ideas (Dawson, 2000), marketing concepts (Chandrashekaran, Mehta, Chandrashekaran, \& Grewal, 1999; Massey, 1999), and institutional theory (Gooderham et al., 1999), to mention only a few. Participants in change processes can be seen to adopt distinct roles in terms of reliance on rationality, opportunism, comprehensiveness, and the like (Hirschheim \& Sabherwal, 2001).

Van de Ven and Poole (1995) provide a comprehensive typology of change models. Their four categories are:

1. Teleological theories (goal oriented) - Change occurs for rational reasons. People have goals in mind for their organization and seek change to try to meet those goals. Theories of this type would explain Web site change in terms of better accomplishing the organization's objectives.

2. Dialectical theories (conflict) - Change occurs in a process of competition between ideas or for resources to accomplish different objectives. Theories of this type would explain Web site change in terms of changes in the organization's political landscape.

3. Life cycle theories - Change is seen as a normal progression through phases, analogous to the well-known marketing model of brands having a life cycle. The brand is established (birth), enters a youthful phase when the product is seen as fresh and young, matures into a well-known product, and then dies when the brand is old and stodgy. Theories of this type would explain Web site change in terms of desire to refresh an aging brand image.

4. Evolutionary theories - Change occurs because a poor fit exists between the organization and its environment. Theories of this type would explain Web site change in terms of providing a better fit between the Web site of an organization and the Web sites of its peers or competitors in the institutional field. 
These theoretical ideas were operationalized into the following statements, which were used to compose survey questions that could be asked of Webmasters to test each concept. Although other roles are important in organizations (e.g., managers, users, administrators), we decided that the Webmaster role was the one on which we would focus because, in our experience, all major Web projects include one or more people filling this role. We could think of no other category of people that would have as broad an appreciation for Web projects across organizational settings or that would be as likely to be available to discuss completed Web projects.

We believe that these four types of explanation for discontinuous change represent a thorough coverage of the reasons that we were able to find in the literature and in correspondence with other researchers.

1. Rational Change: When Web sites are changed to increase effectiveness or efficiency. Change is required for the organization to accomplish its stated goals. The focus of the change is on the work to be done, the task to be accomplished, and the objectives to be met. Objectives may be internal, focused on efficiency and internal processes, or external, focused on better customer relations. The manager seeking rational goal change will set objectives and establish clear expectations for change outcomes.

2. Political Change: When Web sites are changed to reflect a new regime. A new executive officer or technology officer required the Web site to change as a way to show his/her influence, the "new broom sweeping clean," or to clear out images and mechanisms from the previous regime. It was not a requirement that the site work better or adhere to betteraccepted design principles, just that it be different from the previous site. Users should see that the new site is clearly connected to the new blood in the organization.

3. Marketing Change: When Web sites are changed to freshen up the organization's brand image. Web site design for an organization is a reflection of the organization itself and its "brand". All brands need occasional refreshing. This brand freshness will keep the brand in the consumer's eye and keep the look contemporary. Without routine brand image change a once-novel look will become old and dated, leading to a consumer perception of staleness and stolidity. A changing organization needs a changing brand image.

4. Institutional Change: When Web sites are changed to improve fit with peers. The organization sees itself as being part of an 'organization field,' a collection of similar organizations. These other organizations are the focal organization's reference group. When enough of the reference group changes in a given direction, or even one key referent changes, then the focal organization changes in the same way to maintain a match with the other. The organization changes to keep its membership in the group, so that others can see it as falling in the same group of organizations.

\section{Methodology}

In our prior research, as part of developing the instrument to assess reasons for Web site change, we computed reliability estimates (Cronbach's alpha) to pare down each scale from five to three items, which we felt would be the minimum desirable number for analytic purposes (Ryan et al., 2003). Table 1 shows the reliability estimates for the three-item versions of each scale. The values attained for these scales are acceptable.

Table 1: Reliability estimates for survey scales

\begin{tabular}{|l|l|l|l|l|}
\hline & Rational & Political & Marketing & Institutional \\
\hline Alpha & 0.81 & 0.81 & 0.82 & 0.93 \\
\hline
\end{tabular}


Scale items are shown in Table 2. Scores for the scales represent the importance of the types of explanations for change. The simplest way to compute scale scores is to sum the ratings for items that constitute the scale, with no adjustments. Such totals can be thought of as raw scale scores. Table 3 shows the average raw scale scores for the U.S. state government Web site survey for all participants. Higher scores indicate higher importance. The highest possible score for a scale is 15.

Table 2: Change scale items

\begin{tabular}{|c|c|}
\hline Change Type & Item \\
\hline Rational & The home page was changed to make it more user-friendly. \\
\hline Rational & $\begin{array}{l}\text { The Web design team redesigned the organization's home page to make it } \\
\text { easier for users to find the information they need. }\end{array}$ \\
\hline Rational & $\begin{array}{l}\text { The home page is providing our clientele with better information and services } \\
\text { now that it has been redesigned. }\end{array}$ \\
\hline Political & $\begin{array}{l}\text { The home page was changed because we had a new executive officer who } \\
\text { wanted it changed. }\end{array}$ \\
\hline Political & $\begin{array}{l}\text { We changed the look and feel of the site to reflect the new administration of } \\
\text { the organization. }\end{array}$ \\
\hline Political & $\begin{array}{l}\text { When new executives joined the organization, one of the first things they did } \\
\text { was ask for the home page to be changed. }\end{array}$ \\
\hline Marketing & The old home page had gotten 'old' looking and needed to be freshened. \\
\hline Marketing & $\begin{array}{l}\text { It had been a while since we changed the organization's home page and we } \\
\text { needed a new look. }\end{array}$ \\
\hline Marketing & $\begin{array}{l}\text { The organization had been changing and we needed to change the home page } \\
\text { to better reflect what the organization had become. }\end{array}$ \\
\hline Institutional & We had to change our home page to meet our competition. \\
\hline Institutional & $\begin{array}{l}\text { Other organizations we compare ourselves to had changed their home pages } \\
\text { and we needed to match them. }\end{array}$ \\
\hline Institutional & $\begin{array}{l}\text { We could see that other organizations like us were changing their home pages } \\
\text { so we changed ours. }\end{array}$ \\
\hline
\end{tabular}

Table 3: Average raw scale scores for U.S. state government Web sites

\begin{tabular}{|l|l|l|l|l|}
\hline & Rational & Political & Marketing & Institutional \\
\hline Mean $(\mathrm{N}=34)$ & 13.6 & 6.8 & 11.9 & 9.0 \\
\hline Std. Deviation & 1.89 & 3.08 & 2.83 & 2.93 \\
\hline
\end{tabular}

As the first step in conducting this study, we identified a sample of public and private universities offering degrees at different levels (i.e., Bachelors, Masters, PhD). A comprehensive list of U.S. universities provided by U.S. News and World Report was consulted and a total of 432 universities were randomly selected ( 72 for each of six groupings: public/private by Bachelors/Masters/PhD). 
We then went to the Web and compared the most recent version of each university's home page to archived versions of its home page at the Internet Archive (web.archive.org). We examined successively older versions of the home page, until we found a discontinuous change. In some instances, the first discontinuous change had occurred only a month or two before the most recent university page; in other cases it had occurred a year or two before. Images were created by screen capture of the two sites - one before the discontinuous change and one after it.

We opted to focus on home pages in our efforts to identify discontinuous Web site changes, because we needed to have a clear target of reference in our identification of organizations that had experienced discontinuous Web site change and in our questioning of Webmasters. While it is true that home pages and Web sites are not the same, we made the assumption that substantial changes to home pages correlate highly with substantial changes in Web sites. According to Nielsen and Tahir (2002), "The homepage is the most important page on any website, getting more page views than any other page." We decided to use substantial home page change as a marker for substantial Web site change.

Next we retrieved Webmasters' email addresses from their university sites. Where addresses could be found we sent email messages to the potential participants. Each message contained hyperlinks to the two site images and to a Web based questionnaire. The site image links were included to clarify for the participant what we meant by a discontinuous change and which specific change we were talking about.

Some university sites did not provide a Webmaster email address but instead provided a form for comments. In this case, the form was completed by cutting and pasting in the email message described above. Several weeks after the initial survey email message, a follow-up message was sent to Webmasters who had not yet responded.

Questions used in the survey, other than those constituting the scales of interest, included the following. The first two of these were associated with possible responses as shown. The last two were open response questions, allowing participants to type free-form answers into a text box.

- I would rate the process of changing from the older to the newer home page as very effective. [The scale allowed responses from "strongly agree" (5) to "strongly disagree" (1).]

- Rate whether your work on the home page is more of a managerial nature or a technical nature. [The scale allowed responses of "more managerial" (1) and "more technical" (2).]

- If there are other reasons for the change in your university's home page, please enter the information below. [Responses were captured as free-form answers.]

- We would also be interested in any details that you might like to provide about the process your university went through in changing from the one home page design to the second design and your plans for the next version of the home page. [Responses were captured as free-form answers.]

The second step of this study was to extend the survey to Canadian universities and colleges. A comprehensive list of these was available from the University of Waterloo Canadian Universities list (http://www.uwaterloo.ca/canu/). The same methodology was used as in the previous United States survey, except that a French version of the questionnaire was sent to colleges and universities in Canada with a home page in French.

\section{Findings}

For the U.S. survey, we received usable responses from 163 universities (38\%). Response rates within each of the six cells (public/private by Bachelors/Masters/PhD) varied from $34 \%$ to $44 \%$. 
The number of responses for some of the analyses reported below varies from 163 because some universities had more than one respondent and some respondents did not include identifying information that would allow placement of their data into one of the six cells.

Table 4 shows the average change scale scores by university level. For each scale there were three questions answered from $1=$ strongly disagree to $5=$ strongly agree. These three questions were summed. There are no significant differences in the mean scores by university level for each of the four theoretical reasons for change.

Table 4: Average change scale scores by university level

\begin{tabular}{|l|l|l|l|l|l|}
\hline Level & & Rational & Political & Marketing & Institutional \\
\hline PhD (N=65) & Mean & 13.2 & 6.2 & 11.1 & 8.5 \\
\hline & Std dev & 2.2 & 3.0 & 2.4 & 3.0 \\
\hline & & & & & \\
\hline Masters (N=51) & Mean & 13.1 & 6.6 & 11.2 & 8.8 \\
\hline & Std dev & 2.4 & 3.0 & 2.2 & 2.6 \\
\hline & & & & & \\
\hline Bachelors (N=47) & Mean & 13.3 & 6.3 & 11.1 & 8.6 \\
\hline & Std dev & 1.9 & 3.0 & 2.1 & 2.8 \\
\hline
\end{tabular}

Table 5 shows the average change scale scores by public versus private type of university. There are no significant differences in the mean scores by university type for each of the four change reasons.

Table 5: Average change scale scores by university type

\begin{tabular}{|l|l|l|l|l|l|}
\hline University Type & & Rational & Political & Marketing & Institutional \\
\hline Public (N=82) & Mean & 13.2 & 6.2 & 11.0 & 8.5 \\
\hline & Std dev & 2.4 & 3.0 & 2.2 & 2.9 \\
\hline & & & & & \\
\hline Private (N=81) & Mean & 13.2 & 6.4 & 11.3 & 8.7 \\
\hline & Std dev & 1.9 & 3.1 & 2.3 & 2.7 \\
\hline
\end{tabular}

Because there were no significant differences in the mean scores by university level or type the responses can be aggregated. The upper part of Table 6 shows this aggregation. Examination of means indicates that the rational model best explains the reasons for Web site change in a university setting, followed by marketing, institutional, and political explanations. Comparing the upper and lower parts of Table 6 we can see that in two different populations of Webmasters - state government and universities, this ordering of the reasons for Web site change is constant. The mean scores of each model are also similar. 
Table 6: Overall average change scale scores

\begin{tabular}{|l|l|l|l|l|l|}
\hline & & Rational & Political & Marketing & Institutional \\
\hline University sites & Mean & 13.2 & 6.3 & 11.1 & 8.7 \\
\hline$(\mathrm{N}=163)$ & Std dev & 2.2 & 3.0 & 2.2 & 2.8 \\
\hline & & & & & \\
\hline $\begin{array}{l}\text { U.S. state govern- } \\
\text { ment sites }\end{array}$ & Mean & 13.6 & 6.8 & 11.9 & 9.0 \\
\hline$(\mathrm{N}=34)$ & Std dev & 1.9 & 3.1 & 2.8 & 2.9 \\
\hline
\end{tabular}

To test the statistical significance of apparent differences in change scale scores, we conducted a Friedman ANOVA on ranks analysis (Conover, 1999). A non-parametric analog of the parametric two-way analysis of variance, the Friedman analysis of variance involves calculations on ranks, although the original observations may have been captured on a higher scale, as our data were. This analysis is useful if there is doubt concerning the distributions of scale scores to be analyzed. Given that our interest in this research was in the relative importance of the four change scales and that we were not confident about the normality of distributions of scale scores, we deemed this statistical technique to be most appropriate.

Table 7 shows the results of the Friedman analysis. As suggested by Conover (1999, p. 370), the test statistic, $\mathrm{T}_{2}$, was used to assess whether there is any overall difference across scale scores. Since the attained value for $\mathrm{T}_{2}$ was significant, it became meaningful to examine multiple comparisons. The calculated magnitude for significant differences between rank sums for scale scores in this study was 30.46. Actual differences between rank sums for the different scale scores indicated a statistically significant ordering of scale scores: rational $>$ marketing $>$ institutional $>$ political.

Table 7: Analysis of variance (non-parametric) on change scale scores

\begin{tabular}{|c|c|c|c|c|}
\hline \multicolumn{5}{|c|}{ Friedman test } \\
\hline Variables & Rational & Political & Marketing & Institutional \\
\hline Mean rank & 3.65 & 1.38 & 2.95 & 2.02 \\
\hline
\end{tabular}

\begin{tabular}{|c|c|}
\hline \multicolumn{2}{|c|}{ Test of overall difference } \\
\hline $\begin{array}{c}\text { Treatment average sum of } \\
\text { squares of ranks }\end{array}$ & 6181.5 \\
\hline Number of blocks & 208 \\
\hline $\mathrm{T}_{2}(\mathrm{~F})$ & 358.70 \\
\hline $\mathrm{p}$-value & 0.0001 \\
\hline
\end{tabular}

\begin{tabular}{|c|c|}
\hline \multicolumn{2}{|c|}{ Multiple comparison tests } \\
\hline Critical t-value (621 d.f.) & 1.96 \\
\hline $\begin{array}{c}\text { Calculated critical rank } \\
\text { sum difference }\end{array}$ & 30.46 \\
\hline
\end{tabular}




\begin{tabular}{|l|l|l|}
\hline Comparison & $\begin{array}{l}\text { Rank Sum } \\
\text { Difference }\end{array}$ & p-value \\
\hline Rational vs. Marketing & 145.0 & 0.0001 \\
\hline Rational vs. Institutional & 338.5 & 0.0001 \\
\hline Rational vs. Political & 470.5 & 0.0001 \\
\hline Marketing vs. Institutional & 193.5 & 0.0001 \\
\hline Marketing vs. Political & 325.5 & 0.0001 \\
\hline Institutional vs. Political & 132.0 & 0.0001 \\
\hline
\end{tabular}

University Webmasters were also asked to rate the process of changing from the older to the newer Web site as very effective $(1=$ strongly disagree to $5=$ strongly agree). Table 8 shows an indication that university Webmasters rated the change process as more effective the lower the degree level granted by their institution. This tendency was not statistically significant $(\mathrm{F}=1.903, \mathrm{p}=.152)$. There was no difference between public and private universities in ratings of effectiveness made by their Webmasters.
Table 8: Average rating of change effectiveness by university level and type

\begin{tabular}{|l|l|l|}
\hline Level & & Effectiveness \\
\hline $\mathrm{PhD}(\mathrm{N}=65)$ & Mean & 3.86 \\
\hline & Std dev & 1.12 \\
\hline Masters $(\mathrm{N}=51)$ & Mean & 3.98 \\
\hline & Std dev & 0.99 \\
\hline Bachelors $(\mathrm{N}=47)$ & Mean & 4.23 \\
\hline & Std dev & 0.84 \\
\hline Public/Private & & Effectiveness \\
\hline Public $(\mathrm{N}=82)$ & Mean & 3.98 \\
\hline & Std dev & 1.03 \\
\hline Private $(\mathrm{N}=81)$ & Mean & 4.04 \\
\hline & Std dev & 1.01 \\
\hline & \multicolumn{2}{|l}{} \\
\hline
\end{tabular}

University Webmasters rated their work on the Web site as more of a managerial nature or a technical nature. Table 9 below shows that university Webmasters who reported that their work is of a more technical nature saw the process of Web site change as more political than did their more managerial colleagues.

Table 9: Average change scale scores by Webmaster role

\begin{tabular}{|l|l|l|l|l|l|}
\hline Webmaster Role & & Rational & Political & Marketing & Institutional \\
\hline Managerial (N=80) & Mean & 13.3 & 5.6 & 10.8 & 8.2 \\
\hline & Std dev & 1.9 & 2.7 & 2.5 & 2.8 \\
\hline Technical (N=78) & Mean & 13.2 & 7.1 & 11.5 & 9.0 \\
\hline & Std dev & 2.2 & 3.2 & 2.0 & 2.8 \\
\hline & & & & & \\
\hline F & & 0.009 & 9.964 & 3.673 & 3.345 \\
\hline Significance & & ns & .002 & .057 & .069 \\
\hline
\end{tabular}


An analysis was made of the correlations between the rated effectiveness of the change process and the change type (see Table 10). Webmasters who reported that the discontinuous changes in their universities' Web sites were made for rational reasons also reported a more effective change process. The same was true for marketing reasons, but the relationship, while still statistically significant, was much less strong. There was no connection found between Institutional reasons for change and an effective change process. The more the reasons for change were political, the more our respondents reported that the change process was less effective.

Table 10: Correlations of effectiveness ratings by change type

\begin{tabular}{|l|l|l|l|l|}
\hline & Rational & Political & Marketing & Institutional \\
\hline Correlation & .605 & -.205 & .214 & .023 \\
\hline Significance & $\mathrm{p}<.01$ & $\mathrm{p}<.01$ & $\mathrm{p}<.01$ & $\mathrm{~ns}$ \\
\hline $\mathrm{N}=163$ & & & & \\
\hline
\end{tabular}

For the Canadian sample of 124 colleges and universities, 43 responses were received, a rate of $35 \%$. Table 11 shows that the mean scores for each change reason. An analysis of variance found that there were no significant differences between the means for each change type between the two countries.

Table 11: Average change scale scores by country

\begin{tabular}{|l|l|l|l|l|l|}
\hline Country & & Rational & Political & Marketing & Institutional \\
\hline U.S.A. $(\mathrm{N}=163)$ & Mean & 13.2 & 6.3 & 11.1 & 8.7 \\
\hline & Std dev & 2.2 & 3.0 & 2.2 & 2.8 \\
\hline & & & & & \\
\hline Canada (N=43) & Mean & 13.1 & 6.1 & 10.8 & 8.3 \\
\hline & Std dev & 2.4 & 2.7 & 2.6 & 3.2 \\
\hline
\end{tabular}

\section{Discussion}

The results of the study show that, at least in the opinion of university Webmasters involved in discontinuous Web site changes, rational considerations were the most important determinants of change. Across all participants, the reasons captured by the rational scale ranked as the most important. Marketing reasons were next in importance, followed by institutional reasons and political reasons.

The results are interesting in many ways. Although it was not obvious in advance that rational motives would dominate the others, it is appealing to believe that the overriding concerns of those designing Web sites for universities and state governments should involve such notions as providing students and citizens with better information and services. The general finding of this study that this is so is in accord with much wisdom in IS research and practice. It is frequently the case that justifications for systems development projects have to do with improving functionality, ease of use, and so on. The findings here echo that line of reasoning.

The second interesting finding is that, in retrospect, it makes sense that marketing reasons would be viewed as having been second in importance. Organizations of all kinds, including universities and state governments, can be thought to be in competition for the attention of people using the Web. When pages go unchanged for a while, it may well be that people will cease to find them 
interesting. It may also be that Web sites are subject to laws of fashion. If this is the case, a Web site developed at one time, and perhaps in fashion then, would come to be viewed as out of style after some time. An "old" looking Web site could reflect lack of anything new to say or lack of awareness of how sites are currently constructed. Either way, these are not judgments that most organizations would want their potential Web site visitors to form.

The third result of interest from this study is that reasons for change did not vary by university level or type. Web changes at universities offering doctoral degrees were no more driven by institutional reasons for change than their counterparts at Masters and Bachelors schools. Changes at private schools were no more justified by such reasons than those at public schools.

The fourth interesting finding from this study is that the lack of differences in the results by country implies that university Webmasters in the two countries are similar in their reasons for Web site change.

There are potential limitations to the conclusions that one can draw based on the data collected in this study. As is true with many other survey studies, it could be the case that the responses of participants reflect factors other than accurate perceptions of the situations and events in question. It could be true that some of the university Webmasters responding to the survey were unaware of the real reasons for the changes in which they participated. As noted above, we chose Webmasters because this role is one that is involved in almost all major Web projects, unlike other roles, such as Dean, Provost, Marketing Manager, or Vice President. To the extent that Webmasters are unaware of what is "really going on," the findings of this study could be inaccurate. Although we believe that Webmasters provide a useful source of information about the reasons for Web site change, it remains possible that they are not aware of all the reasons for Web change projects in their organizations. This is particularly worrisome if certain reasons (e.g., political ones) are more difficult to be aware of for some people in the organization than for other people.

It also could be true that for some of the participants it is not acceptable to admit the real motives for change. Perhaps there exists a social norm among university Webmasters, whether technical or managerial, to justify their actions in rational, rather than political or other, terms. That is to say, there may be some expectation, among the larger community of Webmasters to which all Webmasters in this study belong, to behave rationally_maybe Webmasters simply are like this. Unfortunately, this study does not allow explicit investigation of such possibilities.

Dawson and Buchanan (2005) argue that technological change occurs as part of complex political processes that are not well described in terms of simple, linear event sequences. They suggest that multiple, competing narratives are necessary to capture the reality of such processes and the contexts in which they occur. According to Dawson \& Buchanan, when corporate descriptions of change processes are produced, they tend to present the firm in a positive light, sanitize the story concerning the change, and describe how the change occurred in a neat fashion. Because change can be the result of power struggles, from their perspective, to understand it requires multiple interpretations of events focusing on the exercise of power over time- - before, during, and after change occurs.

An additional limitation of this study, one that is true of most studies, is that it does not address a number of interesting, tangential issues. One of the most interesting of these issues has to do with differences in the kinds of rational (or marketing or institutional or political) reasons that are used in justification of discontinuous Web site change in university settings. It could be argued, for example, that some rational reasons have more weight than others.

Many modern universities might view their primary Web sites as entrances to their e-learning systems, although others might employ distinct e-learning sites on the Internet or on an intranet. For these universities, rational reasons for Web site change related to changes in their e-learning 
systems might dominate other rational reasons (such as recruitment, advancement, enrollment, etc.); for others, e-learning as a driver of Web site change might be less important.

Another form of rational reason would center on fundamental changes in the technology with which Web sites are constructed. As one example, portal technologies have become commonplace, and non-portal sites are quite different from portal sites. Organizations may come to adopt such technologies - and be forced to make major, apparently discontinuous, changes to their sites - for technical reasons, apart from the reasons considered here. This study lays the groundwork for research on these questions by establishing that rational reasons (as a broad category) are important in explaining discontinuous changes in university Web sites.

\section{Conclusion}

The findings of this study have several implications for those who are involved in managing Web sites change for universities. First, the results here imply that the most compelling reasons for Web site change are rational ones--those that involve increasing effectiveness or efficiency. Changes required for the organization to accomplish its stated goals may be the ones that will be viewed as normal, perhaps leading to perceptions of the change being reasonable. When the focus of the change is on the work to be done, the task to be accomplished, and the objectives to be met, the motive for the change might be more easily understood and familiar. Speculatively, rational reasons for Web site change may be the preferred ones to use in arguing for the approval of Web projects, especially if the argument occurs in a typical university context.

Next, marketing reasons for Web site change may be more likely to be viewed as plausible in university settings. In situations where a university's brand image is important, decision makers may view proposed projects to freshen up a Web site as reasonable endeavors. Arguments based in marketing notions - change to promote brand freshness, to keep the university's brand in the consumer's eye, or to assure a contemporary look - may also be perceived as usual, perhaps raising their chances of success.

Finally, arguments for Web site changes that are based on institutional or political reasons may be viewed as more unusual. While this does not mean that such arguments are inappropriate or unlikely to succeed, they may be more likely to stand out, which could mean that they will be more closely scrutinized by decision makers. Whether this would mean that proposals with such justifications would be rejected by decision makers more frequently than those justified by rational or marketing arguments is not clear. This research suggests the need for additional study, although it does not allow a definitive answer to such questions.

Reasoning along these lines is not without possible controversy. It could be that there is substantial entanglement of the various types of reason considered in this study. For instance, what reasons would be operative when a school changes its Web site in response to a reorganization of its fundamental units (Schools to Faculties) ? ${ }^{1}$ The reorganization might be the result of marketing, institutional, or political pressures; even if the immediate reasons for Web site change mapped to the change in structure (i.e., were rational, as the term is used here), is there need to consider the overall chain of reasons? Although our purpose has been to assess the proximate reasons for Web site changes, additional consideration of more distant chains of reasoning could have value.

In future work, an imperative will be to examine the roles that information plays in discontinuous change processes. There are at least two senses in which information is crucial to this. The first is that information informs the individuals who initiate and manage Web site changes. They make change-related judgments based on information concerning the organization and its information

\footnotetext{
${ }^{1}$ Thanks to an anonymous reviewer for this example.
} 
technology, even if such judgments perhaps should not be viewed as strictly, or even predominantly, rational (Dawson \& Buchanan, 2005). What information is employed by these individuals? (What do they consider about the uses to which the Web site is put? What do they know about the stakeholders of the Web site, existing and proposed? What characteristics of the firm, its activities, its environment, and its strategic path do they consider? ) What characteristics of this information make a difference? (Is it "hard" information? Is it reliable or confirmable?) Do discontinuous changes in Web sites result from discontinuous changes in information concerning the relationship between the existing Web site and the firm? A better understanding of such information is crucial to developing a complete appreciation of Web site changes, particularly discontinuous ones.

The second sense in which information ought to be emphasized in future research on discontinuous Web site change is in the informational content of the Web site. Informational content has been viewed as the dominant contribution of many Web sites (McGovern \& Norton, 2002). They state that while "knowledge is the useful stuff inside our heads," information is a process by which knowledge is communicated, and content "is how we formally structure our knowledge" (p. 13). Although their approach to information change in Web sites is inherently incremental, their point is well taken. Especially if a basic configuration of Web sites is based on information flow (Azzone et al., 2000), it is important that additional study of Web site change go beyond examining sites visually and somewhat superficially, as was done in this study, to considering information content changes across entire sites in a deep fashion.

This will likely be easier said than done, as there can be complete change in the specific information content in a site without there being any change in the nature of the information in the site. For example, the contents of a site that reports news may contain today almost no information that is exactly the same as what it had a year ago, but it could still contain precisely the same kinds of information. In a university setting, a large amount of the information content might be expected to remain constant periods as long as a year, but it is also conceivable that a great deal of change in the type of information provided can occur, as well. To appreciate fully the nature and causes of discontinuous change surely would require a rigorous way of thinking about and assessing informational changes in the Web site contains, as well as changes in its form, its functionality, and its (apparent or real) purposes.

If future work is to focus on information in either of these senses, it may be desirable to adopt a method that allows for richer understanding of the situations within which Web site change occurs. Perhaps qualitative techniques should be tried, to attempt to capture the multiple competing narratives (Dawson \& Buchanan, 2005) that could be present in situations when political reasons for change are thought to be in effect. If such methods were to be employed, it might be possible to avoid sanitization by individuals or organizations of stories about changes to Web sites. Much work must be done to consider the many ways in which information can change, both the knowledge used in the processes that lead to Web site change and the data conveyed by the Web site.

Beyond more deeply examining the information aspects of discontinuous Web site change in future, and in addition to considering possible qualitative approaches, we intend to develop further the survey instrument employed here, to make it more useful to other researchers. Because the current study was exploratory in nature, it does not provide the evidence needed to claim that the instrument involved is adequate for other settings or purposes; additional validation is required. Such validation will entail consideration in conceptual terms of the nature of information available to respondents, as well as the reliability of scores, the stability of the factor structure for scores, and suitability for populations of respondents other than Webmasters.

Future studies might be longitudinal in nature, looking for the specific triggers for discontinuous change in Web sites. One might undertake administering a validated version of the scale devel- 
oped here in some large sample of organizations on a repeated basis. After some length of time elapses, one might look for discontinuous changes in the Web sites, and assess how the organizations involved had undergone changes in each of the four variables that make up the instrument.

Future research might fruitfully examine the types of arguments that are employed in proposals for major Web site changes and the disposition of such proposals. By better understanding the reasons that discontinuous changes in Web sites occur, it may be possible to appreciate when and for what reasons proposals for such changes succeed. To the extent that Universities and other institutions gain such understanding, they will improve their abilities to manage their Web site change processes more effectively.

\section{References}

Aoyama, M. (2002). Continuous and discontinuous software evolution: Aspects of software evolution across multiple product lines. Proceedings of IWPSE, Vienna, Austria, ACM.

Azzone, G., Bianchi, R., \& Noci, G. (2000) The company's Web site: Different configurations, evolutionary path. Management Decision, 38(7), 470-479.

Barrett, M., \& Heracleous, L. (2001). Organizational change as discourse: Communicative actions and deep structures in the context of information technology implementation. Academy of Management Journal, $44,755-778$.

Chandrashekaran, M., Mehta, R., Chandrashekaran, R., \& Grewal R. (1999). Market motives, distinctive capabilities, and domestic inertia: A hybrid model of innovation generation. Journal of Marketing Research, 36, 95-112.

Conover, W. J. (1999) Practical nonparametric statistics (3 ${ }^{\text {rd }}$ ed.). New York: John Wiley \& Sons.

Dawson, P. (2000). Technology, work restructuring and the orchestration of a rational narrative in the pursuit of 'management objectives': The political process of plant-level change. Technology Analysis and Strategic Management, 12(1), 39-58.

Dawson, P., \& Buchanan, D. (2005) The way it really happened: Competing narratives in the political process of technological change. Human Relations, 58(7), 845-865.

Gooderham, P. N., Nordhaug, O., \& Ringdal, K. (1999). Institutional and rational determinants of organizational practices: Human resource management in European firms. Administrative Science Quarterly, 44, 507-531.

Fetterly, D., Manasse, M., Najork, M., \& Wiener, J. L. (2004) A large-scale study of the evolution of Web pages. Software: Practices \& Experience, 34(2), 213-237.

Hirschheim, R., \& Sabherwal, R. (2001). Detours in the path toward strategic information systems alignment. California Management Review, 44(1), 87-108.

Massey, G. R. (1999). Product evolution: A Darwinian or Lamarckian phenomenon? The Journal of Product and Brand Management, 8(4), 301-318.

McGovern, G., \& Norton, R. (2002) Content critical. London: Pearson Education Ltd.

Nielsen, J. \& Tahir, M. (2002). Homepage usability. 50 websites deconstructed. Indianapolis, IN: New Riders.

Ryan, T., Field, R. H. G., \& Olfman, L. (2003). The evolution of U.S. state government homepages from 1997 to 2002. International Journal of Human-Computer Studies, 59, 403-430.

Van de Ven, A. H., \& Poole, M. S. (1995). Explaining development and change in organizations. Academy of Management Review, 20, 510-540.

Weick, K. E., \& Quinn, R. E. (1999). Organizational change and development. Annual Review of Psychology, 50, 361-86. 


\section{Biographies}

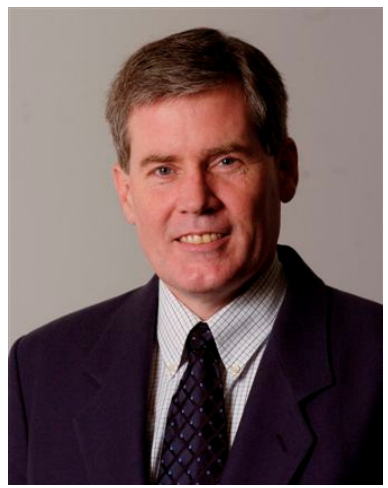

Terry Ryan is Associate Professor in the School of Information Systems and Technology and Co-Director (with Lorne Olfman) of the Social Learning Software Lab $\left(\mathrm{SL}^{2}\right)$ at Claremont Graduate University. His teaching and research interests are in the design, development, and evaluation of information systems to support teaching and learning, online discussions and dialogues, and preparing for and responding to emergencies. He has published articles in Communications of the AIS, Data Base, Information \& Management, International Journal of Human-Computer Studies, International Journal of Knowledge Management, Journal of Computer Information Systems, Journal of Database Management, Journal of Information Systems Education, and other outlets.

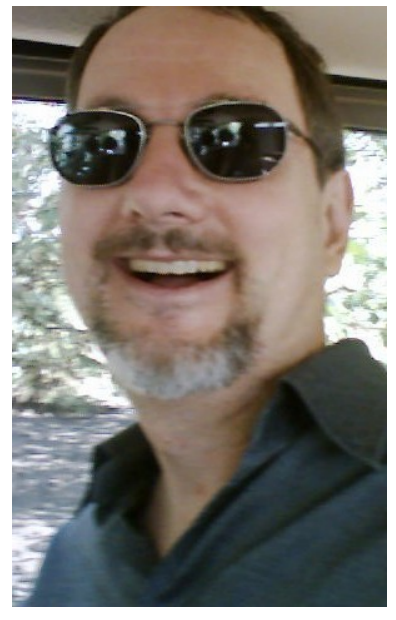

Dr. Richard Field is a professor of Strategic Management and Organization at the School of Business, University of Alberta in Edmonton Canada, where he has been since 1985. His interests are in the intersection of organizational behavior and information systems and he is currently working on the question of how and why organizational web site designs change over time. His first degree was in Mathematics and Computing Science from the University of Waterloo (1973), followed by an MBA in Quantitative Methods from McMasterUniversity (1976), and finally a $\mathrm{PhD}$ in Organizational Behavior from the University of Toronto (1981). Dr. Field has been a sabbatical visitor at the School of Information Science at Claremont Graduate University during the $2001 / 2002$ academic year. His web address is http://www.bus.ualberta.ca/rfield/ and e-mail is Richard.Field@ualberta.ca

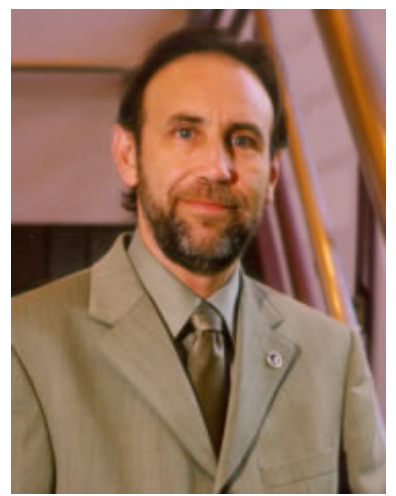

Lorne Olfman is Dean of the School of Information Systems and Technology and Fletcher Jones Chair in Technology Management at Claremont Graduate University (CGU) and. He came to Claremont in 1987 after graduating with a PhD in Business (Management Information Systems) from Indiana University. Lorne's research interests include: how software can be learned and used in organizations, the impact of computer-based systems on knowledge management, and the design and adoption of systems used for group work. Along with Terry Ryan, Lorne co-directs the Social Learning Software Lab (SL $\left.{ }^{2}\right)$. A key component of Lorne's teaching is his involvement with doctoral students; he has supervised 39 students to completion. Lorne is an active member of the Information Systems community. 